\author{
Stanisław FIC ${ }^{1}$ \\ Przemysław BRZYSKI ${ }^{2}$ \\ Andrzej SZEWCZAK ${ }^{3}$ \\ Monika JAROSZ-HADAM ${ }^{4}$
}

\title{
WYBRANE WŁAŚCIWOŚCI LEKKICH KOMPOZYTÓW NA BAZIE WYPEŁNIACZY CELULOZOWYCH DO ZASTOSOWANIA W BUDOWNICTWIE EKOLOGICZNYM
}

\begin{abstract}
Dynamiczny rozwój współczesnej technologii materiałowej w budownictwie energooszczędnym oparty jest na poszukiwaniu rozwiązań ekologicznych pozwalających na ograniczenie kosztów produkcji i wbudowania na miejscu budowy, a w konsekwencji na wykonywaniu obiektów przyjaznych dla środowiska. Istotne znaczenie, oprócz kosztów, ma tutaj także dostępność, łatwość zastosowania, skuteczność oraz opcjonalne dalsze kierunki rozwoju danego rozwiązania. Dzięki temu coraz szersze zastosowanie znajdują materiały pochodzenia naturalnego oraz materiały będące odpadami procesów przemysłowych lub recyklingu. W przypadku budownictwa energooszczędnego jednym z kryteriów poddanych badaniom jest możliwość uzyskania materiałów budowlanych o niskim współczynniku przewodzenia ciepła charakteryzujące się jednocześnie odpowiednią wytrzymałością. Poniższe opracowanie opisuje doświadczalną próbę wykonania kompozytu na bazie wapna, cementu portlandzkiego, pucolan, kruszywa lekkiego, słomy i włókna lnianego i łodygi konopnej. W pierwszej części przedstawione zostały receptury wykorzystane do wykonania próbnych zarobów spoiw. Na podstawie uzyskanych wyników badań średniej wytrzymałości spoiw na ściskanie określono przydatność poszczególnych spoiw do wykonania kompozytu. W drugiej części przedstawiono efekt wykorzystania spoiwa o najlepszych parametrach wytrzymałościowych do wykonania dwóch kompozytów w oparciu o dodatek kruszywa lekkiego oraz lnu (pociętej słomy i włókna) i konopi (pocięty rdzeń). Porównano także otrzymane wyniki właściwości mechanicznych (spoiw i kompozytów) oraz cieplnych - współczynnik przewodzenia ciepła uzyskanych kompozytów W opra-
\end{abstract}

${ }^{1}$ Autor do korespondencji: Stanisław Fic, Politechnika Lubelska, 20-618 Lublin, telefon: 81 5384443, e-mail: s.fic@pollub.pl

${ }^{2}$ Przemysław Brzyski, Politechnika Lubelska, 20-618 Lublin, telefon: 81 5384448, e-mail: p.brzyski@pollub.pl

3 Andrzej Szewczak, Politechnika Lubelska, 20-618 Lublin, telefon: 81 5384762, e-mail: a.szewczak@pollub.pl

${ }^{4}$ Monika Jarosz-Hadam, Państwowa Szkoła Wyższa im. Jana Pawła II, 21-500 Biała Podlaska, e-mail: m.jarosz-hadam@dydaktyka.pswbp.pl 
cowaniu zawarto także wnioski z badań oraz określono możliwe dalsze kierunki rozwoju zaproponowanych rozwiązań w oparciu o nowe doświadczenia.

Słowa kluczowe: len, konopia, wapno, materiały budowlane, spoiwo

\section{Wstęp}

Ekologiczne materiały budowlane są coraz powszechniej stosowane w budownictwie energooszczędnym. Zaostrzające się regulacje prawne w celu ograniczenia emisji gazów cieplarnianych oraz wykorzystania innowacyjnych rozwiązań w zakresie inżynierii materiałowej są skuteczną metodą na poszukiwanie naturalnych materiałów, których wykorzystanie w budownictwie wiązało by się z licznymi korzyściami. Istotnym aspektem jest stosowanie materiałów wykonanych ze składników naturalnych, których wpływ na środowisko byłby korzystny i zgodny z ogólnie przyjętym (w wielu dziedzinach techniki) trendem minimalizacji szkodliwości technologii wytwarzania i wbudowywania tego rodzaju materiałów. Dobrym przykładem są bloczki ze słomy na spoiwie glinianym - materiały, które stosowane były powszechnie w odległych czasach a dziś powraca ich przydatność w budownictwie. Co prawda istnieje szereg materiałów budowlanych, których wykorzystanie byłoby prostsze, ale niekorzystne z punktu widzenia konieczności zachowania zasady zrównoważonego rozwoju.

Alternatywą dla słomy i gliny może być włókno oraz słoma lniana a także konopna oraz wapno i składniki pucolanowe. Uprawa lnu w Polsce w ostatnich latach zmniejsza się ze względu na wzrost popularności tkanin syntetycznych w przemyśle odzieżowym. Przeprowadzone zostały badania nad właściwościami włókien lnianych wykorzystanych w kompozytach [2] oraz kompozytów na bazie spienionej zaprawy z udziałem słomy i włókien lnianych do zastosowań w budownictwie $[4,5]$. Nowe zastosowanie mogłoby przywrócić atrakcyjność upraw lnu tym bardziej, że wykorzystane mogą być, poza włóknami, również części zdrewniałe - paździerze. Konopie wykorzystywane są do produkcji materiałów budowlanych np. we Francji i Wielkiej Brytanii jako wypełnienie konstrukcji szkieletowych lub jako izolację termiczną dachu. W wyżej wymienionych krajach oraz w Słowacji były już przeprowadzane badania nad możliwością zastosowania konopi w budownictwie $[1,3,6]$. Zaletą konopi jest ich duża zdolność do pochłaniania $\mathrm{CO} 2 \mathrm{z}$ atmosfery w czasie uprawy. Jako spoiwo pożądany jest naturalny materiał, którym może być wapno $\mathrm{w}$ połączeniu $\mathrm{z}$ odpowiednimi dodatkami wpływającymi na poprawę właściwości wytrzymałościowych kompozytu. Rozwój technologii produkcji materiałów ekologicznych będzie bowiem obejmował coraz większy zakres zarówno badań ich właściwości jak i wykorzystania w praktyce (w budynkach).

Celem artykułu jest przedstawienie wybranych właściwości kompozytów wykonanych $\mathrm{z}$ wymienionych wyżej materiałów do zastosowania jako materiał ścienny w budownictwie, spełniający funkcję konstrukcyjno-izolacyjną jednocześnie. 


\section{Zakres badań i materiały użyte do badań}

Zakres badań składał się badań wstępnych, których celem było opracowanie receptury spoiwa użytego w kompozycie oraz dalszych badań dotyczących porównania podstawowych właściwości mechanicznych (wytrzymałość na ściskanie), fizycznych (gęstość objętościowa, szczelność, porowatość, nasiąkliwość) oraz cieplnych (współczynnik przewodności cieplnej) dwóch kompozytów na bazie spoiwa, które uzyskało najwyższą wytrzymałość na ściskanie.

Podstawowym składnikiem spoiwa jest wapno hydratyzowane $\mathrm{z}$ dodatkiem cementu portlandzki CEM II/A-V, w którym część klinkieru zastąpiona jest odpadem przemysłowym - popiołem lotnym, a ten z kolei wykazując właściwości pucolanowe reaguje $\mathrm{z}$ wodorotlenkiem wapnia. Jako dodatek wykorzystano reaktywną pucolanę - metakaolinit $(\mathrm{S} 2, \mathrm{~S} 3)$ oraz pył krzemionkowy (S4). Receptura S1 nie zawiera dodatków pucolanowych. Została wykonana w celach porównawczych. Użyte $\mathrm{w}$ badaniach pucolany posiadają dużą powierzchnię właściwą, jej cząstki występują w formie amorficznej, co wiąże się z wysoką reaktywnością z wodorotlenkiem wapnia. Tabela 1 przedstawia wagowe proporcje składników w mieszankach.

Tabela 1. Receptury badanych spoiw

Table 1. Formulations of binders tested

\begin{tabular}{|l|c|c|c|c|}
\hline \multirow{2}{*}{\multicolumn{1}{c}{ Składniki }} & S1 & S2 & S3 & S4 \\
\cline { 2 - 5 } & \multicolumn{4}{|c|}{ udział składników wagowo } \\
\hline Wapno hydratyzowane & $\mathrm{W}$ & $\mathrm{W}$ & $\mathrm{W}$ & $\mathrm{W}$ \\
\hline Cement CEM II 42,5 & $\mathrm{C}=50 \% * \mathrm{~W}$ & $\mathrm{C}=50 \% * \mathrm{~W}$ & $\mathrm{C}=45 \% * \mathrm{~W}$ & $\mathrm{C}=45 \% * \mathrm{~W}$ \\
\hline Mikrokrzemionka & - & - & - & $10 *(\mathrm{C}+\mathrm{W})$ \\
\hline Metakaolinit & - & $5 \% *(\mathrm{C}+\mathrm{W})$ & $10 \% *(\mathrm{C}+\mathrm{W})$ & - \\
\hline Woda & $70 \% *(\mathrm{C}+\mathrm{W})$ & $70 *(\mathrm{C}+\mathrm{W})$ & $70 *(\mathrm{C}+\mathrm{W})$ & $70 *(\mathrm{C}+\mathrm{W})$ \\
\hline
\end{tabular}

Zbadano wytrzymałość na ściskanie na próbkach 4x4x16 cm. Ze względu na powolny przebieg reakcji pucolanowej, w czasie 28 dni, próbki przebadano również po 90 dniach (tabela 2).

Tabela 2. Średnia wytrzymałość na ściskanie badanych spoiw

Table 2. The average compressive strength of binders tested

\begin{tabular}{|l|c|c|c|c|}
\hline \multicolumn{1}{|c|}{ F $_{\mathbf{c}}[\mathbf{M P a}]$} & S1 & S2 & S3 & S4 \\
\hline Po 28 dniach & 2,84 & 5,88 & 7,84 & 5,44 \\
\hline Po 90 dniach & 3,60 & 6,82 & 8,73 & 6,95 \\
\hline
\end{tabular}


Na podstawie wyników wytrzymałościowych stwierdzić można, że dodatek pucolany w znaczny sposób wpływa na wzrost wytrzymałości. Dodatek 5\% metakaolinitu w mieszance S2 spowodował dwukrotny wzrost wytrzymałości na ściskanie w stosunku do wyników uzyskanych na próbkach wykonanych wg receptury porównawczej S1. Natomiast zamiana części cementu metakaolinitem w recepturze $S 3$ spowodowała wzrost wytrzymałości o ok. $5 \mathrm{MPa}$ w porównaniu z S1 i ok. $2 \mathrm{MPa}$ w porównaniu z S2. Dodatek pyłu krzemionkowego okazał się mniej efektywny w porównaniu $\mathrm{z}$ dodatkiem metakolinitu, jednak jego obecność również wyraźnie wpłynęła na wzrost wytrzymałości na ściskanie o ok. 3 MPa względem S1.

$\mathrm{Z}$ racji uzyskania najlepszych właściwości wytrzymałościowych próbek z metakaolinitem, do dalszych badań przyjęto spoiwo S3 wg tabeli 1.

Dodatek metakaolinitu wpłynął znacząco na wytrzymałość w ciągu 28 dni. Po upływie 90 dni wytrzymałość wzrosła o $16 \%$ dla spoiwa S2 i $11 \%$ dla spoiw S3. Dodatek mikrokrzemionki ma większy wpływ na późniejszy wzrost wytrzymałości, która po 90 dniach wzrosła o około $28 \%$ w stosunki do wytrzymałości 28 dniowej.

Potwierdzeniem szybciej postępujących reakcji pucolany z Ca(OH $)_{2}$ jest również test fenoloftaleinowy. Próbka S3 polana fenoloftaleiną wykazała najjaśniejszy kolor, świadczący o zanikaniu wolnego wodorotlenku wapnia i jego wiązanie przez składniki spoiwa. Z kolei próbka S1 wykazała żywy, malinowy kolor świadczący o odczynie zasadowym materiału i stosunkowo dużej, w porównaniu z S3, zawartości $\mathrm{Ca}(\mathrm{OH})_{2}$.

W dalszej części badań wykonano dwa kompozyty, pierwszy z nich - K1, wykonano $\mathrm{z}$ użyciem lnu, natomiast drugi - K2, z użyciem łodygi konopi (Rys. 1).

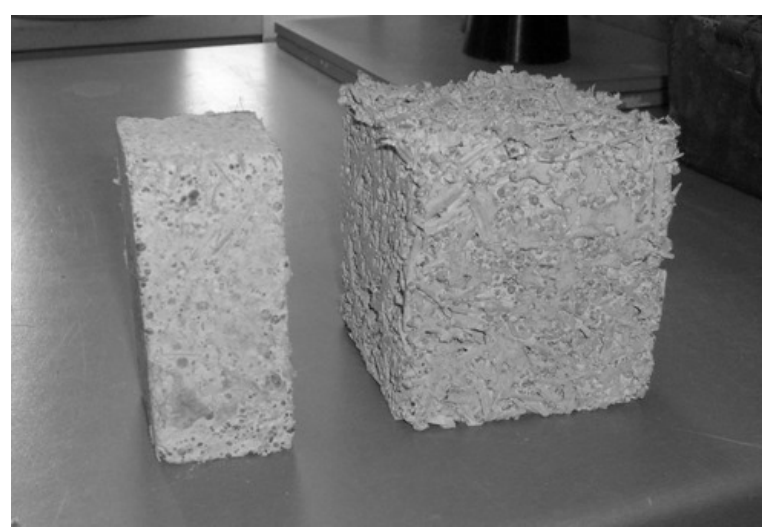

Rys. 1. Badane kompozyty - K1 (strona lewa); K2 (strona prawa)

Fig. 1. Composites tested - K1 (left side); K2 (right side) 
Wybrane właściwości lekkich kompozytów na bazie wypełniaczy celulozowych... $\quad 65$

Wykorzystano len w postaci mieszanki: pociętej na ok. 20mm niewymłóconej słomy lnianej oraz pociętych włókien technicznych o długości 15-20 mm (Rys. 2). Objętościowa ilość lnu w mieszance wynosiła $150 \%$ względem objętości spoiwa. Ze względu na wysoką nasiąkliwość lnu, wstępnie namoczono go w wodzie by ograniczyć ubytek wody zarobowej w trakcie wykonania mieszanki, a także oczyścić z pyłów i zanieczyszczeń. Łodygi konopi pocięto na kawałki o długościach 10-30mm w ilości $150 \%$ objętościowo względem spoiwa (Rys.2). W celu poprawy urabialności zastosowano superplastyfikator na bazie eterów polikarboksylowych. Obniżenie gęstości oraz poprawę właściwości cieplnych kompozytu osiągnięto stosując również lekkie kruszywo drobne szkło piankowe w ilości 75\% objętościowo w stosunku do spoiwa.

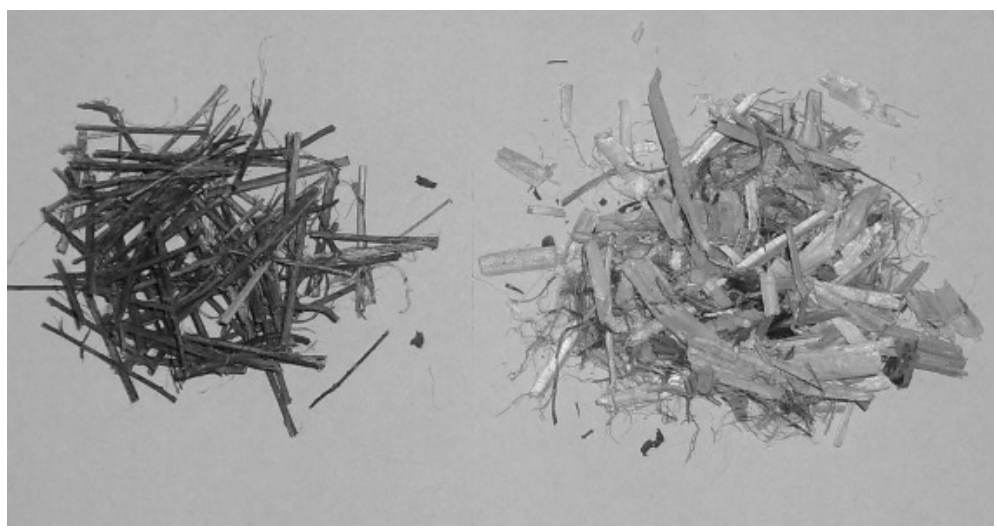

Rys. 2. Pocięta słoma lniana (po lewej) oraz pocięty rdzeń konopi (po prawej)

Fig. 2. Chopped flax straw (on left) and chopped hemp core (on right)

\section{Właściwości kompozytów}

\subsection{Właściwości fizyczne kompozytów}

Zbadano gęstości objętościowe mieszanki lnu oraz mieszanki konopi w stanie luźnym. Wyniosły one ok. $50 \mathrm{~g} / \mathrm{dm}^{3}$ dla lnu oraz $100 \mathrm{~g} / \mathrm{dm}^{3}$ dla konopi. Przyjmując jako punkt odniesienia jednakowe proporcje objętościowe lnu i konopi w stanie luźnym, kompozyt zawierający len po zagęszczeniu uzyskał jednak zdecydowanie większą gęstość z tego względu, że słoma lniana jest bardziej ściśliwa, zwłaszcza po namoczeniu w wodzie. Chcąc wyrównać gęstości objętościowe kompozytów należałoby odmierzać składniki w stanie zagęszczonym. Ilość kruszywa lekkiego jest jednakowa w obu kompozytach. Wyniki wybranych właściwości fizycznych kompozytów przedstawia tabela 3.

Kompozyt K1 uzyskał gęstość o ok. $30 \%$ większą niż K2, co bezpośrednio przekłada się na różnicę w pozostałych właściwościach fizycznych. 
Tabela 3. Właściwości fizyczne badanych kompozytów

Table 3. Physical properties of the composites tested

\begin{tabular}{|l|c|c|}
\hline \multicolumn{1}{|c|}{ Właściwość } & K1 & K2 \\
\hline Gęstość objętościowa $\left[\mathrm{g} / \mathrm{cm}^{3}\right]$ & 0,72 & 0,53 \\
\hline Szczelność [\%] & 31,0 & 24,0 \\
\hline Porowatość [\%] & 69,0 & 76,0 \\
\hline Nasiąkliwość [\%] & 48,0 & 53,0 \\
\hline
\end{tabular}

Materiał wykazuje dużą nasiąkliwość rzędu 50\%, co jest ściśle związane $\mathrm{z}$ jego dużą porowatością rzędu $70 \%$ oraz znaczną zawartością materiału organicznego, zwłaszcza słomy lnianej, która bardzo szybko wchłania wodę . Większa część wody, którą materiał jest w stanie wchłonąć, absorbowana jest już w pierwszym minutach po zanurzeniu kompozytu w wodzie. Zjawisko to można opóźnić lub ograniczyć stosując hydrofobizację powierzchniową lub strukturalną. Wysoka porowatość wiąże się ze znaczą przepuszczalnością materiału, co zapewni niezbędną migrację pary wodnej, potrzebną w konstrukcjach drewnianych oraz dobre właściwości cieplne materiału.

\subsection{Właściwości mechaniczne kompozytów}

Po 28 dniach przechowywania próbek w warunkach laboratoryjnych zbadano wytrzymałość na ściskanie na sześciu próbkach sześciennych 10x10x10cm, z każdej receptury. Wyniki przedstawia wykres (Rys.3).

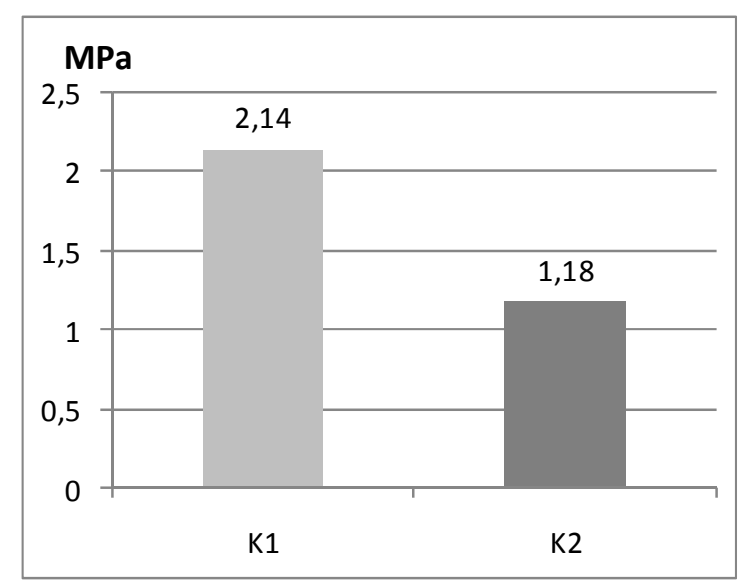

Rys. 3. Średnia wytrzymałość na ściskanie badanych kompozytów

Fig.3. The average compressive strength of the composites tested 
Wybrane właściwości lekkich kompozytów na bazie wypełniaczy celulozowych... 67

Kompozyt K1 uzyskał prawie dwukrotnie większą wytrzymałość (2,14 MPa) niż K2. Związane jest to $\mathrm{z}$ większą gęstością materiału. Wyniki badanej serii próbek są powtarzalne. Nie odnotowano znaczących różnic w wytrzymałości.

Materiał poddany sile ściskającej odkształca się w sposób plastyczny. Graniczna wytrzymałość pod maksymalnym obciążeniem utrzymuje się przez pewien czas, po czym następuje powolny spadek wytrzymałości. Plastyczny charakter pracy kompozytu jako materiału pozwoli na przystosowanie się do możliwych odkształceń konstrukcji budynku.

\subsection{Właściwości cieplne kompozytów}

W celu sprawdzenia wpływu naturalnych wypełniaczy na izolacyjność cieplną, zbadano współczynnik przewodności cieplnej w płytowym aparacie Bocka na próbkach $25 \times 25 \times 5 \mathrm{~cm}$. Porównano przewodność cieplną zakładając 2 średnie temperatury pomiędzy płytą grzejną a chłodzącą $-12,5^{\circ} \mathrm{C}$ i $22,5^{\circ} \mathrm{C}$. Poniższy wykres przedstawia wartości współczynnika $\lambda$ (Rys. 4).

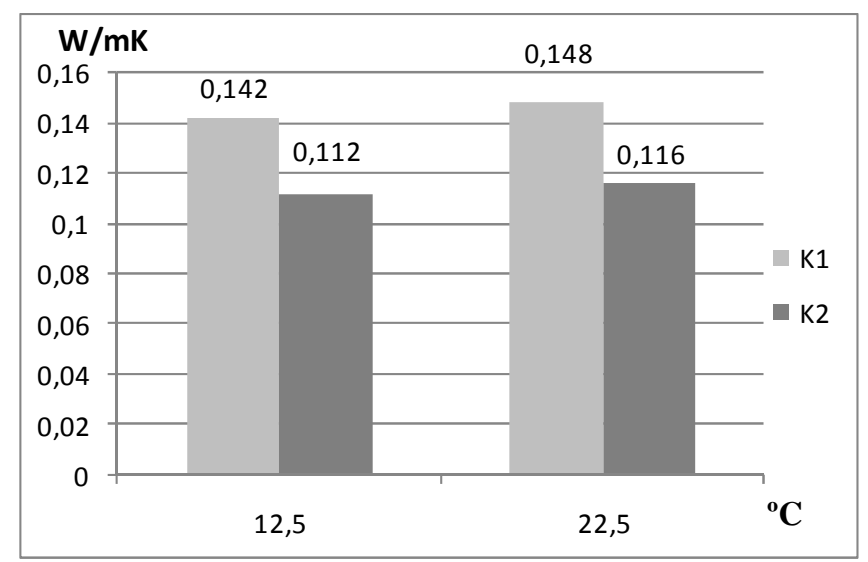

Rys. 4. Współczynnik przewodności cieplnej badanych kompozytów

Fig. 4. The thermal conductivity coefficient of the composites tested

Rdzeń konopi wykazuje przewodność cieplną równą $0,048 \mathrm{~W} / \mathrm{mK}$ dzięki swej porowatej strukturze [3]. Słomy lnianej nie zbadano pod kątem przewodności cieplnej jednak może być ona porównywalna ze słomą zbożową wykorzystywaną w domach ze słomy, czyli 0,052-0,08 W/mK [8]. Zastosowane kruszywo lekkie o współczynniku przewodności cieplnej równym 0,06-0,07 W/mK również wpłynęło po dobre właściwości izolacyjne kompozytu [9].

Wydajność izolacyjna związana jest z gęstością materiału, modyfikowaną poprzez stosunek spoiwa do wypełniacza oraz sposobem układania i zagęszczania kompozytu a w konsekwencji z jego porowatością. Kompozyt K1 ze wzglę- 
du na większą gęstość związaną z większym udziałem spoiwa w porównaniu z K2 uzyskał wyższy współczynnik przewodności cieplnej . Średnie wartości $\lambda$ to $0,15 \mathrm{~W} / \mathrm{mK}$ dla $\mathrm{K} 1$ oraz $0,11 \mathrm{~W} / \mathrm{mK}$ dla $\mathrm{K} 2$. Różne średnie wartości temperatur, wynikające z założonych różnych temperatur płyty dolnej i górnej wywierają minimalny wpływ na wynik. Mniejszą wartość $\lambda$ uzyskano zadając średnią temperaturę $12,5^{\circ} \mathrm{C}$.

Docelowym zastosowaniem kompozytu K2 jest wypełnienie drewnianej konstrukcji szkieletowej oraz kompozytu K1 jako bloczki ścienne . Aby spełnić obowiązujące wymagania związane z granicznym współczynnikiem przenikania ciepła dla ścian zewnętrznych $\mathrm{U}=0,25 \mathrm{~W} / \mathrm{m}^{2} \mathrm{~K}$ [7], należałoby dołożyć warstwę materiału termoizolacyjnego. Przykładowe rozwiązanie pokazano w tabeli 4.

Tabela 4. Konfiguracja grubości warstw ściennych oraz odpowiadająca im wartość „U”

Table 4.. Configurations of wall layers thickness and the corresponding value of " $U$ "

\begin{tabular}{|c|c|c|c|}
\hline Kompozyt & $\begin{array}{c}\text { Grubość } \\
{[\mathrm{mm}]}\end{array}$ & $\begin{array}{c}\text { Wełna mineralna } \\
\lambda=0,039 \mathrm{~W} / \mathrm{mK}[\mathrm{mm}]\end{array}$ & $\begin{array}{c}\mathbf{U} \\
{\left[\mathbf{W} / \mathbf{m}^{2} \mathbf{K}\right]}\end{array}$ \\
\hline K1 & 400 & 80 & 0,21 \\
\hline K2 & 400 & 50 & 0,21 \\
\hline
\end{tabular}

\section{Podsumowanie}

Zaprezentowane $\mathrm{w}$ artykule badania miały na celu ustalenie przydatności wypełniaczy organicznych - odpadów z lnu i konopi - do wykonania kompozytu o dobrych właściwościach konstrukcyjno-izolacyjnych do wykonywania ścian w budynkach. Kompozyt K1 z dodatkiem słomy i włókien lnianych miał większą gęstość objętościową, posiadał wytrzymałość na ściskanie średnio o 100\% wyższą niż kompozyt K2. Współczynnik przewodzenia ciepła był o 27\% niższy w przypadku kompozytu z dodatkiem paździerzy konopnych. Było to wynikiem mniejszej gęstości objętościowej kompozytu K2 w porównaniu z K1 (a tym samym większej porowatości). Zaobserwowano i ustalono wstępnie zależność pomiędzy gęstością objętościową, wytrzymałością materiału a jego współczynnikiem przewodzenia ciepła. Należy zauważyć, że pomimo większej wartości współczynnika $\lambda$ kompozytu K1, jest on niski, co pozwala na wykorzystanie w/w materiałów jako wypełnienia drewnianych konstrukcji szkieletowych i uzyskanie wymaganej izolacyjności cieplnej przegrody zewnętrznej przy minimalnym udziale dodatkowej izolacji termicznej lub bez jej użycia, w zależności od planowanej grubości ściany. Przy grubości ściany wynoszącej $45 \mathrm{~cm}$ wykonanej $\mathrm{z}$ kompozytu $\mathrm{K} 2$, współczynnik $\mathrm{U}$ wynosi $0,24 \mathrm{~W} / \mathrm{m}^{2} \mathrm{~K}$ co jest zgodne $\mathrm{z}$ warunkami technicznymi $\left(\mathrm{U} \leq 0,25 \mathrm{~W} / \mathrm{m}^{2} \mathrm{~K}\right)[7]$.

Wytrzymałość kompozytów regulowana była odpowiednim składem spoiwa. W celu ustalenia najkorzystniejszego rozwiązania materiałowego przepro- 
Wybrane właściwości lekkich kompozytów na bazie wypełniaczy celulozowych... 69

wadzono badania spoiw wykonanych wg 4 receptur. Do dalszych badań wytypowano jako najkorzystniejszy materiał, spoiwo z dodatkiem metakaolinitu, które uzyskało największą wartość wytrzymałości zbadanej po 28 i 90 dniach. Wprowadzenie domieszki pucolanowej jest wskazane aby przyspieszyć wiązanie, co umożliwiłoby możliwie najszybszy termin rozformowania deskowania na budowie. Kompozyty zawierają kruszywo lekkie - szkło piankowe, które wpłynęło na otrzymanie małej gęstości objętościowej $\left(0,5-0,7 \mathrm{~kg} / \mathrm{dm}^{3}\right)$ i niskiego przewodnictwa cieplnego kompozytów $(0,11-0,14 \mathrm{~W} / \mathrm{mK})$.

Przeprowadzone na dwóch seriach próbek badania stanowią podstawy do uznania słomy lnianej i konopnej za dobry, z punktu widzenia termoizolacyjności otrzymanego kompozytu, wypełniacz organiczny. Porównując oba materiały pod względem właściwości fizyko-mechanicznych stwierdzono, że odpady z konopi są lepszą alternatywą dla lnu, ze względu na mniejszą przewodność cieplną, porównywalną nasiąkliwość oraz możliwość ograniczenia ilości spoiwa, co jest korzystne z ekonomicznego punktu widzenia oraz przekłada się na otrzymanie mniejszej gęstości kompozytu, zachowując wystarczającą wytrzymałość.

Wykorzystanie lnu i konopi w budownictwie energooszczędnym otwiera także drogę do dalszego poszukiwania materiałów o podobnych właściwościach, będących albo pochodzenia naturalnego albo też odpadem produkcji przemysłowej, który musi być zutylizowany - możliwość wykorzystywania takich materiałów pozwala na likwidacje kosztów z tym związanych i pozytywnie wpływa na aspekty ekologiczne.

\section{Literatura}

[1] Allin S.: Building with hemp. Seed Press, 2012.

[2] Arbelaiz A., Ferna'ndez B., Cantero G., Llano-Ponte R., Valea A., Mondragon I.: Mechanical properties of flax fibre/polypropylene composites. Influence of fibre/matrix modification and glass fibre hybridization, Composites: Part A 36, 16371644, 2005

[3] Bevan R., Woolley T.: Hemp Lime Construction: A Guide to Building with Hemp Lime Composites.Bracknell, 2010.

[4] Fic S., Brzyski P., Szeląg M.: Composite based on foam lime mortar with flax fibers for use in the building industry, Ecological and Chemistry Engineering. A, nr 78/2013.

[5] Fic S., Brzyski P., Szeląg M.: Ocenka ważmożności izpolzowania naturalnych kompozytow z dodawką lnianych wołokon w stroitelstwie, Bisnik No 53, str. 393-399, Odessa 2014.

[6] Stevulova N., Terpakova E., Lidalova L., Priganc S., Estokova A., Helcman M.: Hemp as potential component in suitable construction. VI Konferencja Naukowo Techniczna: Zagadnienia materiałowe w inżynierii lądowej MATBUD’11, Kraków 2011. 
[7] Rozporządzenie Ministra Infrastruktury w sprawie warunków technicznych, jakim powinny odpowiadać budynki i ich usytuowanie z dnia 12 kwietnia 2002 r. (Dz.U. $\mathrm{Nr} 75$, poz. 690)

[8] www.strawbale.pl [dostęp 5.11.2014]

[9] www.astra-polska.com [dostęp 5.11.2014]

\title{
SELECTED PROPERTIES OF LIGHTWEIGHT COMPOSITES BASED ON CELLULOSE FILLERS IN ECOLOGICAL BUILDING INDUSTRY
}

\begin{abstract}
S u m m a r y
Dynamic development of modern materials technology in energy-saving building industry is based on search for environmental solutions enabling reduction of production cost and installation on the construction site, which consequently leads to building of eco-friendly objects. In addition to costs, other crucial factors include availability, ease of application, effectiveness, and optionally, further directions of the solution development. This allows for increased use of natural materials, and materials which constitute waste in the industrial processes or are products of recycling. In case of energy-saving building industry, one of the testing criteria is a possibility of achieving the building materials with a low coefficient of thermal conductivity, characterized by the adequate strength at the same time.

This paper describes the experimental test of preparing the composite based on lime, portland cement, pozzolans, lightweight aggregate, flax straw and fiber, and core of hemp for use in building industry. The first part presents the recipes applied to make sample mixing binders. Based on the results of testing the average compressive strength of binders, the suitability of various binders to make the composite has been determined. The second part demonstrates the effect of using a binder with the best strength parameters to prepare two composites based on the addition of a lightweight aggregate and flax (chopped straw and fiber) and hemp (chopped core).

The paper also compares the results of the mechanical properties (binders and composites) and thermal properties - thermal conductivity (composites). The study also includes the conclusions of the research and identifies possible directions of future development of the proposed solutions in light of new experiences.
\end{abstract}

Keywords: flax, hemp, lime, building material, binder

Przestano do redakcji: 27.11.2014 $r$.

Przyjęto do druku: 22.06.2015 r.

DOI:10.7862/rb.2015.36 